\title{
Role of grafting in tolerance to salt stress in melon (Cucumis melo L.) plants: ion regulation and antioxidant defense systems
}

\author{
Şebnem Kuşvuran ${ }^{1 *}\left(\mathbb{D}\right.$, Elif Kaya ${ }^{2} \mathbb{D}$, Ş. Şebnem Ellialtıoğlu ${ }^{3}$ \\ ${ }^{1}$ Kizilirmak Vocational High School, Cankiri Karatekin University, 18100, Cankiri, Turkey. \\ ${ }^{2}$ Graduate School of Natural and Applied Sciences, Cankiri Karatekin University, 18100, Cankiri, Turkey. \\ ${ }^{3}$ Department of Horticulture, Faculty of Agriculture, Ankara University, 06110, Ankara, Turkey.
}

\section{How to Cite}

Kuşvuran, Ş., Kaya, E., Ellialtıoğlu, Ş, Ş. (2021). Role of Grafting in Tolerance to Salt Stress in Melon (Cucumis melo L.) Plants: Ion regulation and antioxidant defense systems. Biotech Studies, 30(1), 22-32. https://doi.org/10.38042/biotechstudies.932376

\section{Article History \\ Received 15 February 2021 \\ Accepted 26 April 2021 \\ First Online 3 May 2021 \\ Corresponding Author \\ Tel.: +90 5326841679 \\ E-mail: skusvuran@gmail.com}

\section{Keywords}

Cucumis melo

Grafting

Ion accumulation

Rootstock

Salinity

\section{Introduction}

Salinity is one of the most crucial abiotic conditions and the cause of reduced plant growth, development, and production worldwide, especially in arid and semiarid areas, in which there is insufficient precipitation, and the soils contain high concentrations of salt. Salt stress paves the way for morphological, physiological, and biochemical response changes in plants. Salinity is pertinent to many conditions, such as an imbalance in nutrition, changes in processes of metabolism, and cell and chloroplast membrane distortion (Sarabi et al., 2017). Sodium (Na) is an important cation that is soluble in a lot of soils in arid and semiarid areas. When there is a concentrated amount of $\mathrm{Na}$ in the soils, harmful effects can be noticed in plants. One of the essential effects of salinity is a nutritional imbalance. The high amount of $\mathrm{Na}$ and

\begin{abstract} abiotic stress tolerance under conditions such as salinity. Herein, it was aimed to determine if the salt tolerance of two salt-susceptible melon genotypes, SCP-1 and CP-2, could be improved by grafting onto TLR-1 and TLR-2, which are salt-tolerant melon genotypes, and Albatros commercial melon rootstock. The grafted plants were of 0 and $200 \mathrm{mM}$ under greenhouse conditions. The salt-tolerant rootstock significantly diminished the damaging effects caused by salt stress via a reduction in the uptake of $\mathrm{Na}$ and $\mathrm{Cl}$, which enhanced $\mathrm{Ca}$ and $\mathrm{K}$ uptake and micronutrition. Stress regulation. The salt tolerance of the grafted melon seedlings may have partially been the result of the decreased $\mathrm{Na}$ and $\mathrm{Cl}$, and malondialdehyde contents and higher antioxidant enzyme activities.
\end{abstract}

chlorine $(\mathrm{Cl})$ accumulation under salt stress is regarded as destructive to the cellular systems of plants, and not only calcium (Ca) and potassium (K) ions are damaged, but $\mathrm{Na}$ homeostasis also takes place. In order to endure salt stress, plants tend to decrease Na loading into their xylem, thus limiting the accumulation of $\mathrm{Na}$ in their tissues (Tavakkoli et al., 2011). Abiotic stressors such as salinity cause an excessive accumulation of reactive oxygen species (ROS), which could result in protein oxidation, lipid peroxidation, enzyme inactivation, damage to DNA, and/or interaction with other essential plant cell components. To minimize the toxic effects caused by ROS, plants possess various kinds of enzymatic and nonenzymatic antioxidative systems. The enzymatic system comprises superoxide dismutase (SOD), catalase (CAT), ascorbate peroxidase (APX), and glutathione reductase (GR), while nonenzymatic antioxidants comprise reduced glutathione (GSH), 
ascorbate, carotenoids, and tocopherol (Kusvuran et al., 2016).

Over recent decades, there have been several strategies proposed and used to minimize the effects of salt stress on productivity in the field of agriculture, with the aim of facilitating the development and use of highly saline soils. Reclamation of saline soil and soil salinity correction are important agricultural strategies; however, they are temporary and fairly costly. Breeding of resistant genotypes has also been a method used to aid crops such as horticultural crops in improving their resistance to salt stress. However, it is a laborious and complex process because of the polygenic nature of a plant's resistance to salt. As a result of these complexities, using genotypes that are resistant to salinity as a rootstock has been considered a simple and efficient way of improving a crop's resistance to salt stress (Yanyan et al., 2018). Accordingly, discovering new ways to produce plants that are more resilient to effects caused by salt stress remains one of the highest priority objectives. The grafting of genotypes that are high yielding onto salt-tolerant rootstocks is one method that can be used to achieve this objective (Santa-Cruz et al., 2002). It has been estimated that the grafting of rootstock might induce a change in the balance of the hormones in scions, as it causes alterations in the characteristics of the scion, such as plant hydraulics, and the uptake of water and nutrients, which are affected by vascular connection disruptions (Fullana-Pericas et al., 2018). As a result of this, grafting is a widely applied method to improve the salt tolerance of plants by placing a scion that is productive onto a tolerant rootstock, to initiate tolerance against stress by physical means (Simpson et al., 2015). Grafting is considered to be a vital approach that alleviates the consequences of abiotic stress factors, particularly in tomato and melon (Penella et al., 2016). Melon (Cucumis melo L.), of the family Cucurbitaceae, is a significant horticultural crop that is mainly grown in arid and semiarid regions where salt stress remains a serious problem, despite the advanced management techniques that have been developed over the past decades (Ulas et al., 2019).

In the current study, the effects of grafting on the physiological and biochemical responses of plants under salt stress, with salt-tolerant melon genotypes, 'TLR-1 and TLR-2', and Albatros as the rootstocks and saltsusceptible genotypes, SCP-1 and SCP-2, as the scions were investigated. The study evaluated the salt sensitivity of melon seedlings that had been grafted with a rootstock that was salt-tolerant and provided the groundwork for the improvement of salt tolerance via grafting. Furthermore, the relation between the grafting and salt tolerance improvement was determined. Therefore, an investigation of the effectiveness of grafting utilization in order to increase tolerance to salinity in melon, which is an important species in arid and semiarid regions, was conducted herein.

\section{Materials and Methods}

\section{Plant materials and growth conditions}

Three rootstocks, comprising TLR-1 and TLR-2, which were the selected salt-tolerant melon genotypes in the previous study of Kusvuran (2012), and Albatros (Cucumis melo), (Rito Seeds Company, Turkey), which is a commercial rootstock, were used. As the scion, SCP-1 and SCP-2, which are salt-sensitive melon genotypes, were used. All of the rootstocks were grafted with the SCP-1 and SCP-2 scions, and therefore the following graft combinations were obtained: SCP-1/TLR-1, SCP1/TLR-2, SCP-2/TLR-1, SCP-2/TLR-2, SCP-1/Albatros, and SCP-2/Albatros. The control treatment comprised of the 4 genotypes, $C$. melo (TLR-1, TLR-2, SCP-1, and SCP-2) and a commercial variety (Albatros), which were not grafted and allowed to develop their own roots. Grafting was performed according to the one cotyledon method presented by Lee in 1994. Both the grafted and ungrafted plants were repotted into $12-\mathrm{L}$ plastic pots that contained a peat: perlite mixture at a ratio of 2:1. The plants were then maintained under greenhouse conditions which comprised day/night temperatures of $26 \pm 2{ }^{\circ} \mathrm{C}$ and $18 \pm 2{ }^{\circ} \mathrm{C}$, with a relative humidity of $65 \%$ \pm 5 . Each of the pots contained 4 plants, and each experiment was done with 4 replications. In this experiment, the administration of salinity was initialized 13 days after transplanting. On the first day of experiment, the plants were treated with $50 \mathrm{mM} \mathrm{NaCl}$, and the dose was increased by $50 \mathrm{mM} \mathrm{NaCl}$ each day until the day 4, to a total of $200 \mathrm{mM} \mathrm{NaCl}$. In this study, the treated (experimental) and untreated (control) grafted and ungrafted melon plants were all grown for 14 days. Upon conclusion of the experiment, evaluation of the plants was performed via morphological, physiological, and biochemical parameters.

Relative water content (RWC) and leaf water potential $\left(\Psi_{\mathrm{W}}\right)$ : Estimation of the RWC was performed using the method of Turkan et al. (2005). Calculation of the RWC was performed as follows: RWC (\%) $=[(\mathrm{FW}-$ DW) / (TW - DW)] $\times 100$. Here, TW represents the turgid weight after floatation on deionized water for $5 \mathrm{~h}$. The 3rd fully expanded leaf was measured across the middle of the photoperiod to attain the leaf $\Psi_{\mathrm{w}}$ via a pressure chamber (Muries et al., 2013).

\section{Ion concentration}

For the determination of ion contents, the melon leaves and roots were dried for $48 \mathrm{~h}$ at $65{ }^{\circ} \mathrm{C}$. After which, a mill with a 20-mesh sieve was used to grind the samples. The leaf powder was turned into ash for about $6 \mathrm{~h}$ at $550{ }^{\circ} \mathrm{C}$, which was then dissolved in $3.3 \% \mathrm{HCl}$. Atomic absorption spectrometry was used to determine the $\mathrm{Na}, \mathrm{K}, \mathrm{Ca}, \mathrm{Fe}, \mathrm{Mn}, \mathrm{Zn}, \mathrm{Cu}$ concentrations in the roots and leaves. The $\mathrm{Cl}$ concentration in the tissue samples were determined using the titrimetric analysis with silver nitrate $\left(\mathrm{AgNO}_{3}\right)$ via the Mohr method (Dasgan et al., 2018). 


\section{Malondialdehyde (MDA) content}

Measurement of the lipid peroxidation was calculated using the MDA level determined by the thiobarbituric acid (TBA) reaction (Heath \& Packer, 1968) of the supernatant at $10,000 \times g$ at $4^{\circ} \mathrm{C}$ for $10 \mathrm{~min}$, the absorbance was read at $532 \mathrm{~nm}$ and values were subtracted if they corresponded to non-specific absorption at $600 \mathrm{~nm}$.

\section{Photosynthetic pigments}

The method suggested by Arnon (1949) was used to determine the total carotenoid, chlorophyll a (Chla), and chlorophyll $b$ (Chlb) contents. The leaf pigment extracted was performed with $80 \%(\mathrm{v} / \mathrm{v})$ acetone and a Shimadzu UV mini-1240 spectrophotometer (Kyoto, Japan) was used to measure the absorbance of the extraction at 663,645 , and $470 \mathrm{~nm}$.

\section{Antioxidant enzyme activities}

A mortar and pestle were used for extraction of the enzymes from $0.5 \mathrm{~g}$ of the leaf tissue, in addition to $5 \mathrm{~mL}$ of extraction buffer that contained $50 \mathrm{mM}$ of potassiumphosphate buffer, at $\mathrm{pH} 7.6$, and $0.1 \mathrm{mM}$ of disodium ethylenediaminetetraacetate. Centrifugation of the homogenate took place for $15 \mathrm{~min}$ at $15,000 \times \mathrm{g}$, and the supernatant fraction was used to perform the enzyme assay. The preparation operations for the enzyme extraction were all done at $4{ }^{\circ} \mathrm{C}$. The SOD assay was performed according to the method of Cakmak \& Marschner (1992), via monitoring the reduction of the superoxide radical $\left(\mathrm{O}_{2}^{-}\right)$-induced nitro blue tetrazolium at $560 \mathrm{~nm}$. Monitoring of the disappearance of hydrogen peroxide was used for the determination of the CAT activity. Measurement of the ascorbate consumption from its absorbance at $290 \mathrm{~nm}$ was performed to determine the APX activity. The amount of enzyme required to consume $1 \mu \mathrm{mol}$ of ascorbate $\mathrm{min}^{-1}$ was determined as 1 unit of APX activity (Cakmak \& Marschner, 1992). From the absorbance of nicotinamide adenine dinucleotide phosphate (NADPH) at $340 \mathrm{~nm}$, measurement of its enzyme-dependent oxidation was used to determine the GR activity. The volume of the enzyme that oxidized $1 \mu \mathrm{mol}$ of $\mathrm{NADPH} \min ^{-1}$ was defined as 1 unit of GR activity.

\section{Statistical analysis}

The plot design used for the experiment was completely randomized, comprising 4 replicates. The mean values were compared using the Tukey multiple range test. Statistical significance was accepted as $P<0.05$ using SPSS v.13.0 software for Windows (SPSS Inc., Chicago, IL, USA). Data were presented as the mean \pm standard deviation (SD) and error bars represent the standard errors of the means in all of the figures.

\section{Results}

According to the findings of the present study, salt stress conditions inhibited plant development and growth, but these effects varied between combinations, grafting, and non-grafting (Table 1). The growth of the ungrafted melon seedlings was inhibited significantly following the application of $\mathrm{NaCl}$, while the effects of salt stress were less severe in the grafted seedlings. Under salt stress, the fresh and dry weights of the shoot and root, as well as the leaf area, of ungrafted seedlings were reduced by $70 \%, 55 \%, 48 \%, 43 \%$, and $82 \%$, respectively, whereas they were reduced by $33 \%, 24 \%$, $26 \%, 29 \%$, and $26 \%$, respectively, in grafted plants.

In addition, all of the plants that received an application of $200 \mathrm{mM} \mathrm{NaCl}$, SCP-1/TLR-2, SCP-2/TLR-2, SCP-1/Albatros, and SCP-2/Albatros, exhibited growth parameters with the least decrease of all of the grafted combinations.

As a result of the grafting and salt application interaction, the RWC and leaf $\Psi_{\mathrm{W}}$ showed significant difference at $P<0.001$ level. Melon seedlings under salt stress showed decreased RWC at 31\% and it was 33\% in ungrafted plants when compared to the controls (Table 1). However, in the grafted plants, significantly improved RWC was observed at rates of $82 \%$ and $123 \%$ when compared to the salt-stressed ungrafted plants. With the application of $200 \mathrm{mM} \mathrm{NaCl}$, maximum improvement in the RWC was observed with the

Table 1. Effects of rootstock on the growth parameters of the melon seedlings under salt stress

\begin{tabular}{|c|c|c|c|c|c|c|c|c|}
\hline $\begin{array}{c}\text { Graft } \\
\text { Combination }\end{array}$ & $\mathrm{T}$ & $\begin{array}{l}\text { Shoot fresh } \\
\text { weight } \\
\text { (g plant }^{-1} \text { ) }\end{array}$ & $\begin{array}{l}\text { Shoot dry } \\
\text { weight } \\
\text { (g plant }^{-1} \text { ) }\end{array}$ & $\begin{array}{l}\text { Root fresh } \\
\text { weight } \\
\text { (g plant }^{-1} \text { ) }\end{array}$ & $\begin{array}{c}\text { Root dry } \\
\text { weight } \\
\text { (g plant }^{-1} \text { ) }\end{array}$ & $\begin{array}{l}\text { Leaf area } \\
\left(\mathrm{cm}^{2} \text { plant }^{-1}\right)\end{array}$ & $\begin{array}{l}\text { RWC } \\
(\%)\end{array}$ & Leaf $\Psi_{W}$ \\
\hline \multirow{2}{*}{ SCP-1 } & C & $129.21 \pm 10.59^{h}$ & $14.25 \pm 3.56^{d-f}$ & $3.21 \pm 0.09^{f g}$ & $0.30 \pm 0.09^{g-i}$ & $2977.82 \pm 120.44^{\mathrm{d}-\mathrm{f}}$ & $80.00 \pm 6.88^{a-c}$ & $-0.24 \pm 0.09^{\mathrm{ab}}$ \\
\hline & $\mathrm{s}$ & $60.16 \pm 1.41^{j}$ & $8.15 \pm 2.03^{f g}$ & $1.97 \pm 0.37^{\mathrm{h}}$ & $0.18 \pm 0.04^{i}$ & $403.79 \pm 34.83^{h}$ & $31.95 \pm 7.74^{e}$ & $-0.59 \pm 0.04^{g h}$ \\
\hline \multirow{2}{*}{ SCP-1/TLR-1 } & C & $136.67 \pm 4.01^{g h}$ & $15.24 \pm 1.13^{c-f}$ & $4.11 \pm 0.54^{\mathrm{d}-\mathrm{f}}$ & $0.34 \pm 0.05^{\mathrm{g}-\mathrm{i}}$ & $2627.29 \pm 120.04^{f}$ & $81.94 \pm 7.27^{\mathrm{ab}}$ & $-0.22 \pm 0.03^{a}$ \\
\hline & $\mathrm{S}$ & $74.87 \pm 4.33^{j}$ & $10.68 \pm 0.49^{\mathrm{e}-\mathrm{g}}$ & $3.18 \pm 0.07^{f g}$ & $0.25 \pm 0.03^{h i}$ & $1916.19 \pm 139.44^{\mathrm{g}}$ & $61.21 \pm 3.37^{d}$ & $-0.48 \pm 0.04^{e f}$ \\
\hline \multirow{2}{*}{ SCP-1/TLR-2 } & C & $170.42 \pm 10.86^{c-e}$ & $20.35 \pm 1.50^{b-d}$ & $4.35 \pm 0.59^{c-f}$ & $0.40 \pm 0.05^{\mathrm{gh}}$ & $3863.51 \pm 198.22^{\mathrm{ab}}$ & $83.69 \pm 5.78^{\mathrm{ab}}$ & $-0.27 \pm 0.04^{a-c}$ \\
\hline & $\mathrm{S}$ & $131.79 \pm 8.38^{\mathrm{h}}$ & $17.04 \pm 0.72^{b-d}$ & $3.67 \pm 0.25^{e f}$ & $0.35 \pm 0.06^{\mathrm{g}-\mathrm{i}}$ & $3198.09 \pm 345.26^{\mathrm{c}-\mathrm{f}}$ & $71.42 \pm 5.78^{b-d}$ & $-0.37 \pm 0.04^{\mathrm{cd}}$ \\
\hline \multirow{2}{*}{ SCP-1/Albatros } & C & $188.74 \pm 8.27^{\mathrm{bc}}$ & $23.02 \pm 2.92^{\mathrm{ab}}$ & $4.44 \pm 0.44^{c-f}$ & $0.49 \pm 0.10^{f g}$ & $3479.10 \pm 309.52^{\mathrm{b}-\mathrm{e}}$ & $81.33 \pm 5.38^{\mathrm{ab}}$ & $-0.21 \pm 0.03^{a}$ \\
\hline & $\mathrm{s}$ & $141.94 \pm 6.97^{f-h}$ & $18.11 \pm 2.92^{\mathrm{b}-\mathrm{d}}$ & $3.58 \pm 0.16^{\mathrm{ef}}$ & $0.40 \pm 0.05^{g h}$ & $2917.19 \pm 156.93^{\text {ef }}$ & $70.30 \pm 6.43^{b-d}$ & $-0.33 \pm 0.03^{b-c}$ \\
\hline \multirow[b]{2}{*}{$\mathrm{SCP}-2$} & C & $177.71 \pm 5.11^{\mathrm{cd}}$ & $18.15 \pm 2.45^{b-d}$ & $4.74 \pm 0.60^{c-e}$ & $0.62 \pm 0.08^{\text {ef }}$ & $3588.38 \pm 384.52^{\mathrm{a}-\mathrm{d}}$ & $91.38 \pm 4.19^{\mathrm{a}}$ & $-0.27 \pm 0.04^{\mathrm{a}-\mathrm{c}}$ \\
\hline & $\mathrm{s}$ & $60.63 \pm 6.95^{j}$ & $7.79 \pm 1.38^{\mathrm{g}}$ & $2.33 \pm 0.12^{\mathrm{gh}}$ & $0.36 \pm 0.07^{g-i}$ & $982.80 \pm 88.40^{\mathrm{h}}$ & $33.13 \pm 4.13^{\mathrm{e}}$ & $-0.64 \pm 0.05^{h}$ \\
\hline \multirow{2}{*}{ SCP-2/TLR-1 } & $\mathrm{C}$ & $158.77 \pm 8.65^{\mathrm{d}-\mathrm{f}}$ & $19.11 \pm 4.59^{b-d}$ & $5.38 \pm 0.66^{\mathrm{bc}}$ & $0.94 \pm 0.16^{c}$ & $3899.50 \pm 407.65^{a b}$ & $82.06 \pm 3.48^{\mathrm{ab}}$ & $-0.23 \pm 0.03^{\mathrm{a}}$ \\
\hline & $\mathrm{S}$ & $104.85 \pm 8.65^{i}$ & $14.36 \pm 1.05^{d-f}$ & $4.07 \pm 0.30^{d-f}$ & $0.66 \pm 0.04^{d-f}$ & $2710.55 \pm 157.91^{f}$ & $60.34 \pm 8.46^{d}$ & $-0.52 \pm 0.02^{f g}$ \\
\hline \multirow{2}{*}{ SCP-2/TLR-2 } & C & $208.81 \pm 9.57^{\mathrm{ab}}$ & $21.14 \pm 2.94^{a-c}$ & $6.10 \pm 0.46^{\mathrm{b}}$ & $0.87 \pm 0.15^{c d}$ & $4173 \pm 304.59^{\mathrm{a}}$ & $84.28 \pm 4.77^{\mathrm{ab}}$ & $-0.23 \pm 0.04^{a}$ \\
\hline & $\mathrm{s}$ & $159.36 \pm 5.74^{\mathrm{d}-\mathrm{f}}$ & $17.61 \pm 0.87^{b-d}$ & $5.05 \pm 0.59^{b-d}$ & $0.72 \pm 0.07^{\text {de }}$ & $3649.86 \pm 274.01^{a-c}$ & $64.58 \pm 3.12^{\mathrm{cd}}$ & $-0.42 \pm 0.03^{\mathrm{d}-\mathrm{f}}$ \\
\hline \multirow[b]{2}{*}{ SCP-2/Albatros } & C & $215.65 \pm 10.73^{a}$ & $26.94 \pm 4.77^{\mathrm{a}}$ & $7.61 \pm 0.85^{a}$ & $1.55 \pm 0.11^{\mathrm{a}}$ & $3945.19 \pm 233.16^{\mathrm{ab}}$ & $81.84 \pm 7.64^{\mathrm{ab}}$ & $-0.22 \pm 0.03^{a}$ \\
\hline & $\mathrm{s}$ & $153.94 \pm 5.78^{\mathrm{e}-\mathrm{g}}$ & $19.27 \pm 1.06^{\mathrm{b}-\mathrm{d}}$ & $6.22 \pm 0.39^{b}$ & $1.16 \pm 0.06^{b}$ & $3048.54 \pm 372.61^{c-f}$ & $68.83 \pm 6.07^{b-d}$ & $-0.39 \pm 0.02^{\text {de }}$ \\
\hline
\end{tabular}

*Each value represents the mean of four replicates. For each parameter, different superscripted letters represent statistically significant differences at $P \leq 0.05$ according to the Tukey test (T: treatment, S: salinity, C: control). 
Albatros rootstock combination for both SCP-1 and SCP2 , where the increase in RWC was $120 \%$ and $127 \%$. The leaf $\psi_{\mathrm{w}}$ ranged from -0.21 to $-0.64 \mathrm{MPa}$ and was significantly affected by the salt stress. These results showed that grafting promoted a positive influence on the $\Psi_{\mathrm{W}}$ under salt stress (increase of $18 \%$ and $44 \%$ ).

Salt stress generally increased the levels of $\mathrm{Na}$ and $\mathrm{Cl}$ in the tissue samples, with the grafted plants showing a lower concentration in the leaves (decreased by $24 \%$ and $52 \%$, respectively) and roots (decreased by $10 \%$ and $71 \%$, respectively) when compared with the ungrafted plants (Figure 1). Although exposure to $\mathrm{NaCl}$ also elevated the leaf $\mathrm{K}$ levels of the grafted plants (increased by $48 \%$ and $135 \%$ ), the roots of these plants had lower $\mathrm{K}$ concentrations (decreased by $5 \%-15 \%$ more than the roots of the ungrafted plants. Similarly, Ca levels were higher in the leaves (increased by $38 \%$ and $135 \%$ ) of the grafted plants than in the corresponding samples from the ungrafted plants. Finally, concentrations of micronutrients, such as $\mathrm{Fe}, \mathrm{Cu}, \mathrm{Mn}$, and $\mathrm{Zn}$, in the leaves and roots were significantly affected by the melon rootstock, at $12 \%$ and $156 \%$ higher for $\mathrm{Fe}, 27 \%$ and $187 \%$ higher for $\mathrm{Mn}$, and $4 \%$ and $56 \%$ higher for $\mathrm{Zn}$, when compared with the ungrafted salt-stressed plants, whereas the $\mathrm{Cu}$ contents were decreased by an average of $11 \%$ in the leaves (Table 2).
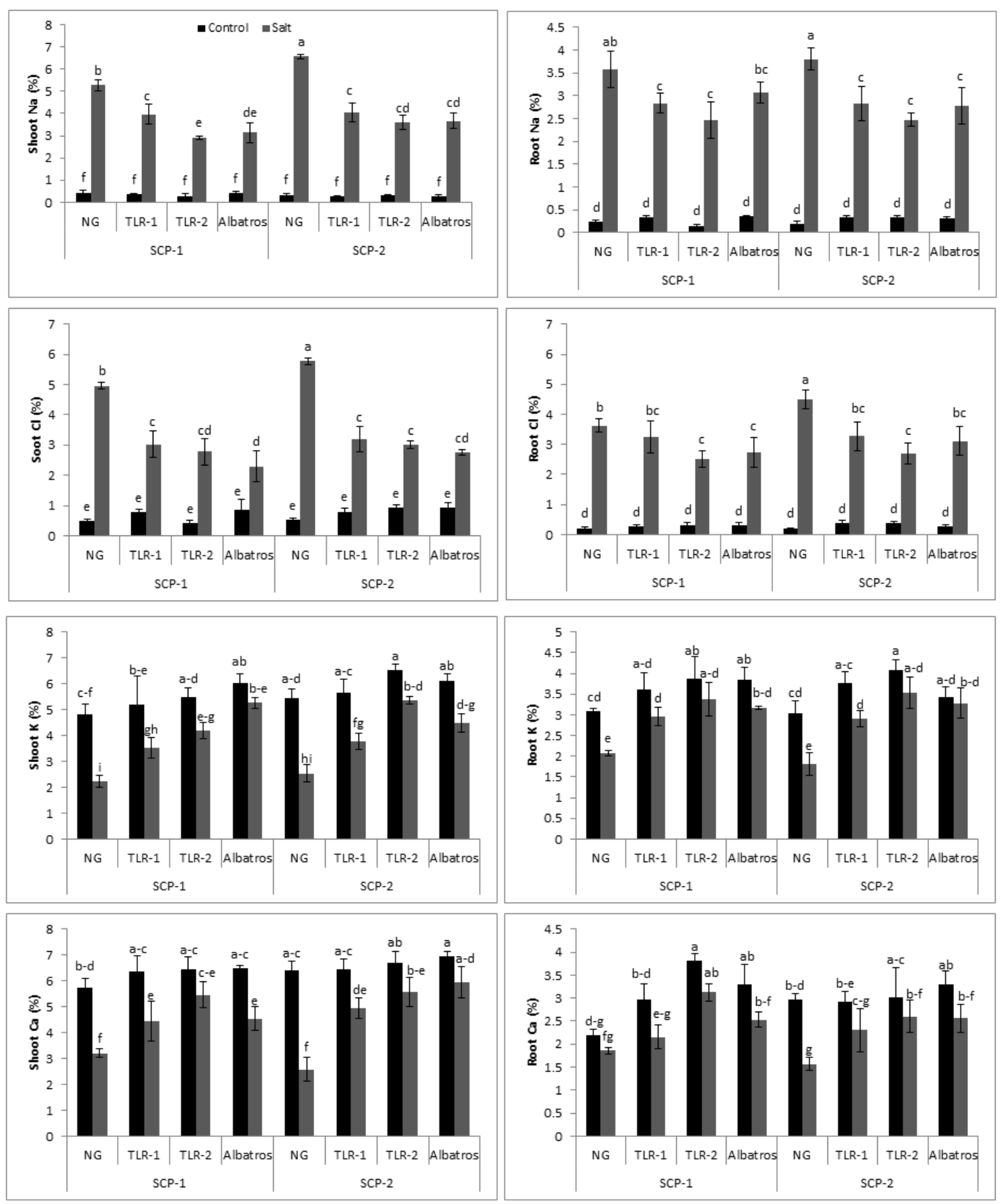

Figure 1. Effects of rootstock on the $\mathrm{Na}^{+}(\mathrm{A}, \mathrm{B}), \mathrm{Cl}^{-}(\mathrm{C}, \mathrm{D}), \mathrm{K}^{+}(\mathrm{E}, \mathrm{F})$, and $\mathrm{Ca}^{2+}(\mathrm{G}, \mathrm{H})$ contents of the melon seedlings under salt stress. Each value represents the mean of four replicates. For each parameter, different letters represent statistically significant differences at $P<0.05$ according to the Tukey test. 


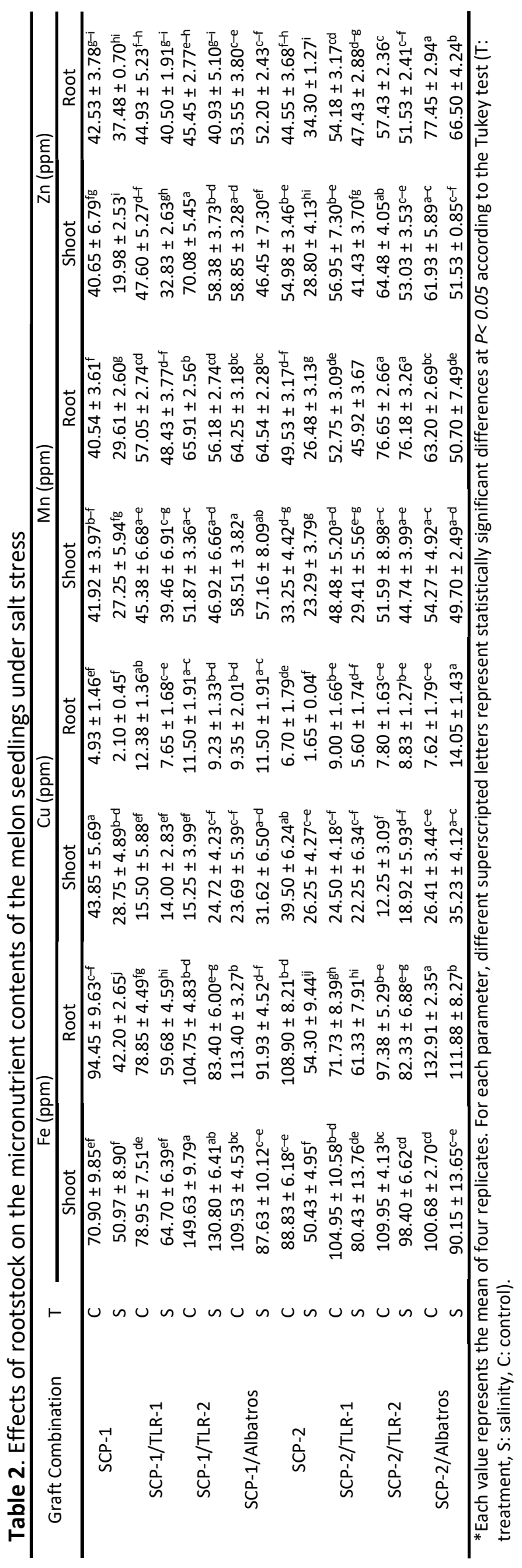

After 14 days of exposure to salt stress, the MDA content was observed to have significantly increased in the ungrafted plants $(P<0.05)$. The highest MDA content was determined in the ungrafted SCP-2 genotype following salt stress $\left(29.9 \mu \mathrm{mol} \mathrm{g}{ }^{-1} \mathrm{FW}\right)$. The lowest MDA concentration under salt stress was observed in the SCP1/TLR-2 combination (13.9 $\left.\mu \mathrm{mol} \mathrm{g} \mathrm{g}^{-1} \mathrm{FW}\right)$.

When the MDA content was considered, the ratio of MDA increased by 834 and $988 \%$ when compared to controls in the ungrafted sensitive genotypes, while this rate varied between 330 and $650 \%$ when grafted with the tolerant genotypes, and a decrease of 17 and $44 \%$ occurred when grafted with the tolerant genotypes (Figure 2). In the control groups, no statistically significant differences were determined in the photosynthetic pigments, such as the Chla, Chlb, and total carotenoid contents, between the plant combinations (Figure 2). However, these parameters significantly decreased with the application of $200 \mathrm{mM}$ $\mathrm{NaCl}$ in both the grafted and ungrafted plants. The photosynthetic pigments decreased by $44 \%$ and $74 \%$, $50 \%$ and $53 \%$, and $55 \%$ and $64 \%$ in the ungrafted genotypes under salt stress when compared with the control groups. On the other hand, the Chla, Chlb, and total carotenoid contents were less affected by salt stress in the SCP-1 and SCP- 2 that had been grafted with rootstock (decrease of $12 \%$ and $39 \%$ ).

In response to salt stress, the antioxidant enzyme activities (SOD, CAT, GR, and APX) increased in both the grafted and ungrafted plants. Moreover, the grafted plants exhibited much higher antioxidant enzyme activities than the ungrafted plants under salt stress (Figure 3). The SOD activity was observed to have increased significantly in the grafted plants, by about $35 \%$ and $115 \%$, when compared with the ungrafted saltstressed plants. In addition to this, the TLR-2 rootstock was noted as a rootstock that exhibited the highest SOD enzyme activity in the SCP-1 and SCP-2 plants (increase of $95 \%$ and $115 \%$, respectively). Salt stress resulted in enhanced CAT, GR, and APX activities in all of the combinations and the greatest activities were seen in the SCP-2/TLR-2 plants, with differences that were significant when compared to the ungrafted plants and the other graft combinations.

The graft combination, the correlation between shoot and root dry weight, shoot and root $\mathrm{Na}$ and $\mathrm{Cl}$ ion contents, MDA and the other parameters of melon plants under salt stress conditions are shown in Table 3. Shoot and root dry weight of salt stressed plants were significantly negatively correlated with shoot and root $\mathrm{Na}$ and $\mathrm{Cl}$ ion contents and MDA concentrations. Similar negative correlations between MDA and all of the other parameters were recorded with the exception of the shoot and root $\mathrm{Na}$ and $\mathrm{Cl}$ ion contents. On the other hand, all physiological (leaf area, RWC, leaf water potential, Chla, Chlb, and total carotenoid contents, ion content (shoot and root $\mathrm{K}, \mathrm{Ca}, \mathrm{Fe}, \mathrm{Cu}, \mathrm{Mn}, \mathrm{Zn}$ ) and antioxidant enzyme activities (SOD, CAT, GR, and APX) 

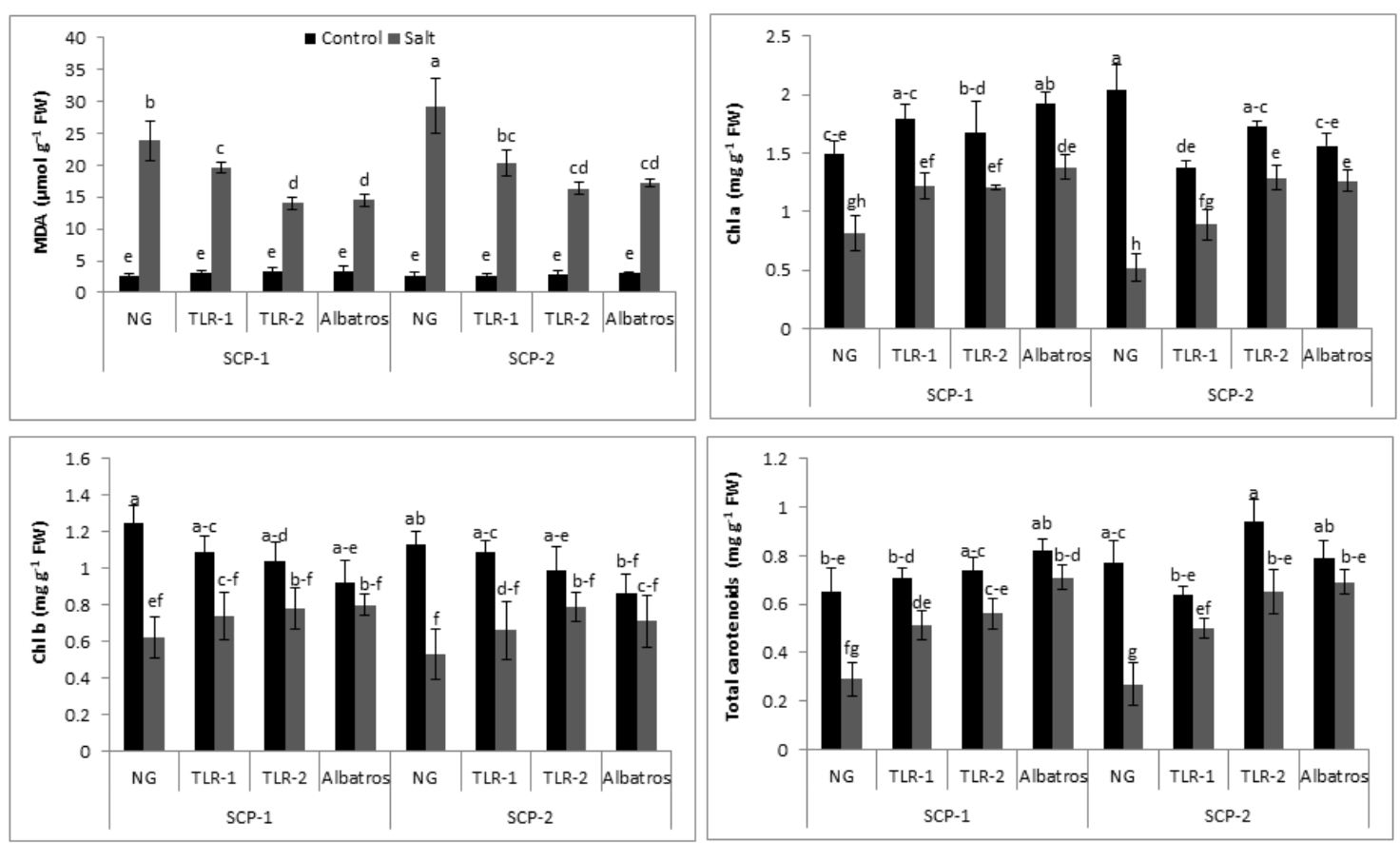

Figure 2. Effects of rootstock on the MDA, Chla, Chlb, and total carotenoid contents of the melon seedlings under salt stress. Each value represents the mean of four replicates. For each parameter, different letters represent statistically significant differences at $P<0.05$ according to the Tukey test.

parameters were significantly positively correlated with shoot and root dry weight under salt stress.

\section{Discussion}

Plants are affected by a high level of salinity in two specific ways: 1) high concentrations of salt in the soil interfere with water absorption in the roots, and 2) high concentrations of salt within the plant can lead to the disruption of numerous biochemical and physiological processes, including the absorption and assimilation of nutrients (Carillo et al., 2011). Grafting was observed to have reduced the negative effects caused by the salt stress in this experiment. Under the effects of salt stress, the grafted plants that were tolerant to salinity were observed to have fresh and dry weights, leaf areas, and shoot lengths and diameters that were closer to those of the control plants when compared to the ungrafted plants. The roots of a plant play a vital role in its development, growth, and survival by transporting water and nutrients up to the stem. It can be concluded that the use of rootstocks that are tolerant to salinity can be beneficial under the influence of salt stress. It is a usual condition that the leaf area of plants decreases when they are exposed to salt stress, which could be a mechanism that is used to reduce the amount of water a plant loses during transpiration. This response of the plants can pave the way for toxic ion retention in the roots, which means that the accumulation of such toxic ions is limited in the aerial parts of the plant. Changes in the characteristics of the cell walls and leaf turgor, and a decrease in photosynthesis rates can be given as examples of different responses under the influence of salt stress, all of which induce a decrease in the total area of the leaf (Acosta-Motos et al., 2017). According to the results of this study, when compared to the control plants, it was observed that the leaf area was considerably reduced under the influence of salt stress. This effect was more influential in the ungrafted plants when compared to the grafted plants. It was reported by Böhm et al. (2017) that the highest tolerance against salt stress was seen in grafted plants with watermelon, with an improvement observed in the plant biomass and leaf area, not a reduction, due to salinity. Colla et al. (2010) observed increased dry weight values and a greater number of leaves in all of the grafted watermelon plants in their study when compared to the ungrafted control group, and it was stated by Penella et al. (2016) that a reduction in the leaf area of ungrafted plants was observed when they were grown under stress, and this condition did not change in any of the combinations of grafted pepper plants. Hence, grafting can reduce the effects of stress on melon growth by salinity. The results showed that grafting the plants onto salt-tolerant TLR-1 and TLR-2 was a successful strategy to improve the tolerance of the salt-sensitive melon seedlings (Table 1). Moreover, grafting plants on to the salt tolerant varieties was an effective approach to increase the salt tolerance of the melon seedlings, which was also found to have improved salt tolerance in tomato, eggplant, and cantaloupe (Zhu et al., 2008).

One of the easiest agricultural parameters used to screen plants for salt or drought tolerance is the RWC (Nxele et al., 2017). When transpiration surpasses water absorption, a decrease in cell turgor occurs resulting in lower levels of RWC and cell volume. Low RWC and turgor causes a delay in plant growth and thus, stomatal conductance also decreases (Hammad and Ali, 2014). 

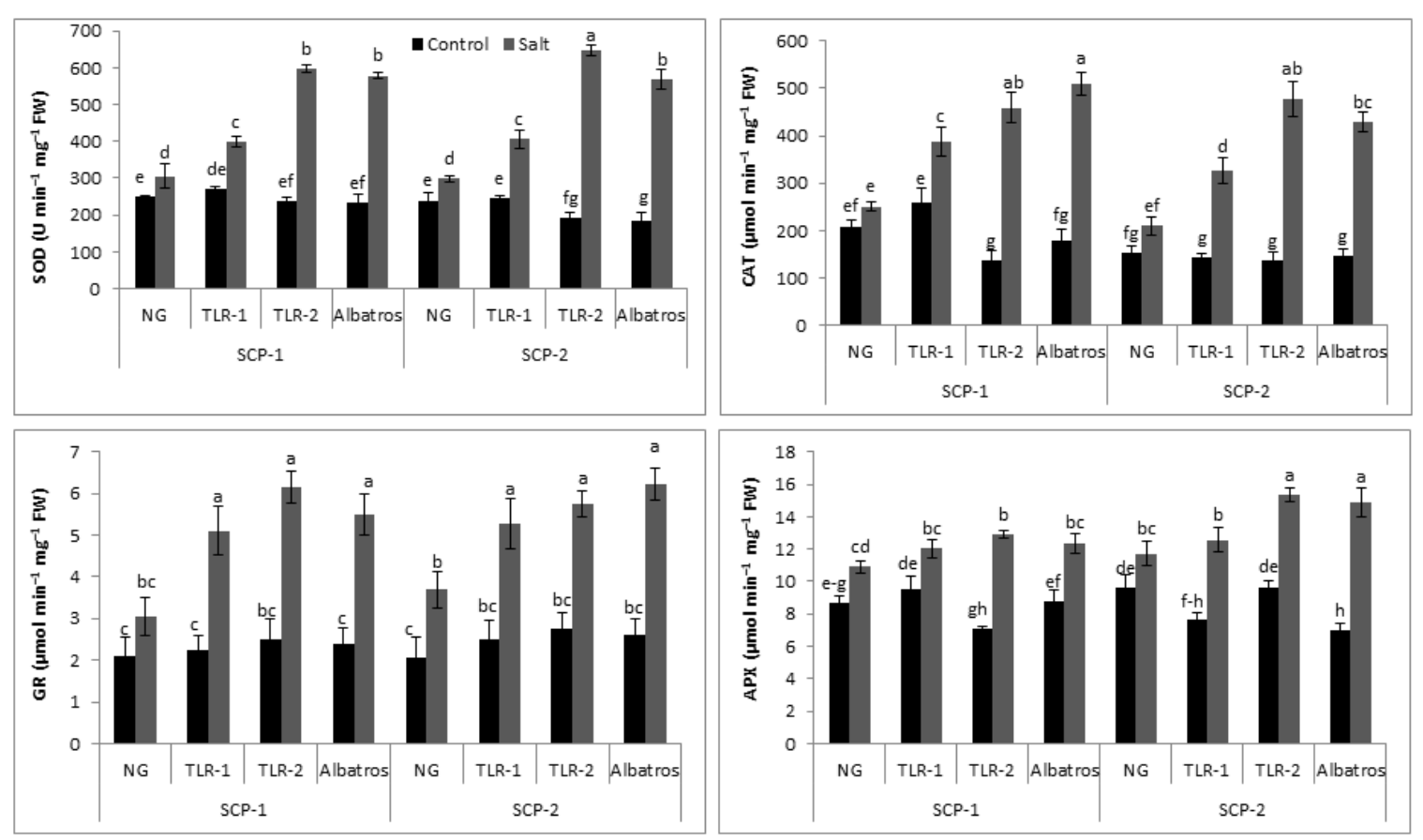

Figure 3. Effects of rootstock on the SOD, CAT, GR, and APX enzyme activities of the melon seedlings under salt stress. Each value represents the mean of four replicates. For each parameter, different letters represent statistically significant differences at $P<0.05$ according to the Tukey test.

Santa-Cruz et al. (2002) recorded a 35\% improvement in the leaf water content of salt-stressed grafted plants while the scion possessed a salt-incorporating character comparable to that of self-grafted plants. Regulation of the plant $\Psi_{W}$ is vital, not simply due to its role in the determination of the response that the plant has salinity, drought, and other stressors, but the effect it has on metabolic processes, which include plant growth as the result of turgor-driven cell expansion (MartinezVilalta and Garcia-Forner, 2016). Plants that are under the influence of salinity and water deficit demonstrate mild dehydration signified by lower $\Psi_{\mathrm{w}}$, because water uptake is more difficult, and the solution of the soil contains less available water (Acosta-Motos et al., 2017). The exposure of plants to water stress and/or salt stress resulted in the greatest negative values for the leaves and stems of the plants, because both passive hydration and salt gathering caused a reduction in the $\Psi_{\mathrm{W}}$ of the leaves. To adjust the osmotic potential, the inorganic ion uptake encountered a lower cost of energy than that matched through the synthesis of organic molecules in the cells (Penella et al., 2015). It was stated by Penella and Calatayud (2018) that the salt tolerance of the scions was affected by the features of the rootstock because stomatal functions were controlled effectively; hence, contributing to a change in the hormonal signaling of plants from the roots to the shoots. The grafted plants of cucumber were observed to have higher rates of photosynthesis and stomatal conductance under the influence of salt stress in comparison with the ungrafted plants (Yang et al., 2006). According to previous studies, it was observed that both stomatal conductivity and values of leaf $\Psi_{\mathrm{W}}$ were reduced; however, the reduction was slightly less in the grafted plants under drought stress (Kiran et al., 2017).

The capability that a plant has to grow under conditions such as high salt stress is related to the ability that the plant has to reserve, categorize, expel, and mobilize $\mathrm{Na}$ ions (Zhu et al., 2008). An efficient way to boost the tolerance of plants to salt is grafting onto tolerant rootstock. In previous studies, the latent mechanisms responsible for the advantageous effects of grafting were examined by researchers from the point of view of the changed homeostasis of ions in the roots when compared to the scion, because the roots of the plants have a vital role in regulating the gathering of $\mathrm{Na}$ in the shoots (Niu et al., 2017). In the current study, the highest accumulation of $\mathrm{Na}$ in the roots and leaves was determined in the ungrafted plants (Figure 1). Hence, the roots of the grafted melon seedlings played a significant role in reducing $\mathrm{Na}$ transport to the roots and leaves, which meant that they were highly important for mitigating $\mathrm{Na}$ toxicity. The lowest accumulation of $\mathrm{Cl}^{-}$ was seen in the grafted plants, whereas the highest accumulation of $\mathrm{Cl}^{-}$was observed in the ungrafted plants. In addition, it was stated that the plants managed to prevent $\mathrm{Cl}^{-}$accumulation in the tissues of their leaves and roots after the process of grafting onto the rootstocks. It was reported by Penella \& Calatayud (2018) that the reduction in the growth of grafted pepper plants under salt stress was mainly associated with the low uptake of salt ions when compared to the ungrafted plants. It was reported by Edelstein et al. (2011) that the most frequent grafting application used for vegetables to improve tolerance to salt was on tomato plants. K, which is a vital macronutrient, importantly partakes in stomatal behaviors, osmoregulation, enzyme activities, and the cells 
Table 3. The graft combination, the correlation between shoot and root dry weight, shoot and root $\mathrm{Cl}$ and $\mathrm{Na}$ ions contents, MDA and other parameters of melon plants under salt stress condition

\begin{tabular}{|c|c|c|c|c|c|c|c|}
\hline & Shoot Dry Weight & Root Dry Weight & Shoot Cl & Shoot $\mathrm{Na}$ & Root Cl & Root $\mathrm{Na}$ & MDA \\
\hline Shoot Fresh Weight & $0.946^{* * *} \&$ & $0.663^{* * *}$ & $-0.763^{* * *}$ & $-0.761^{* * *}$ & $-0.687^{* * *}$ & $-0.613^{* *}$ & $-0.770^{* * *}$ \\
\hline Shoot Dry Weight & 1.000 & $0.652^{* * *}$ & $-0.781^{* * *}$ & $-0.800^{* * *}$ & $-0.690^{* * *}$ & $-0.618^{* *}$ & $-0.832^{* * *}$ \\
\hline Root Fresh Weight & $0.803^{* * *}$ & $0.899^{* * *}$ & $-0.603^{* *}$ & $-0.570^{* *}$ & $-0.459^{* *}$ & $-0.552^{* *}$ & $-0.562^{* *}$ \\
\hline Root Dry Weight & $0.652^{* * *}$ & 1.000 & $-0.338^{\text {ns }}$ & $-0.283^{\text {ns }}$ & $-0.193^{\text {ns }}$ & $-0.342^{\text {ns }}$ & $-0.298^{\text {ns }}$ \\
\hline Leaf Area & $0.895^{* * *}$ & $0.579^{* *}$ & $-0.830^{* * *}$ & $-0.807^{* * *}$ & $-0.693^{* * *}$ & $-0.762^{* * *}$ & $-0.778^{* * *}$ \\
\hline RWC & $0.833^{* * *}$ & $0.418^{*}$ & $-0.878^{* * *}$ & $-0.839^{* * *}$ & $-0.672^{* * *}$ & $-0.592^{* *}$ & $-0.841^{* * *}$ \\
\hline Leaf Water Potential & $0.872^{* * *}$ & $0.347^{\text {ns }}$ & $-0.852^{* * *}$ & $-0.866^{* * *}$ & $-0.722^{* * *}$ & $-0.570^{* *}$ & $-0.878^{* * *}$ \\
\hline Shoot Cl & $-0.781^{* * *}$ & $-0.338^{n s}$ & 1.000 & $0.893^{* * *}$ & $0.792^{* * *}$ & $0.689^{* * *}$ & $0.835^{* * *}$ \\
\hline Shoot $\mathrm{Na}$ & $-0.800^{* * *}$ & $-0.283^{\text {ns }}$ & $0.893^{* * *}$ & 1.000 & $0.756^{* * *}$ & $0.720^{* * *}$ & $0.901^{* * *}$ \\
\hline Shoot K & $0.858^{* * *}$ & $0.480^{*}$ & $-0.825^{* * *}$ & $-0.789^{* * *}$ & $-0.654^{* * *}$ & $-0.628^{* *}$ & $-0.742^{* * *}$ \\
\hline Shoot Ca & $0.820^{* * *}$ & $0.621^{* * *}$ & $-0.795^{* * *}$ & $-0.788^{* * *}$ & $-0.748^{* * *}$ & $-0.696^{* * *}$ & $-0.744^{* * *}$ \\
\hline Shoot Fe & $0.538^{* *}$ & $0.250^{\mathrm{ns}}$ & $-0.578^{* *}$ & $-0.710^{* * *}$ & $-0.563^{* *}$ & $-0.700^{* * *}$ & $-0.649^{* * *}$ \\
\hline Shoot $\mathrm{Cu}$ & $0.231^{\mathrm{ns}}$ & $0.332^{\text {ns }}$ & $0.161^{\text {ns }}$ & $0.044^{\text {ns }}$ & $0.032^{\text {ns }}$ & $0.229^{\text {ns }}$ & $-0.041^{\mathrm{ns}}$ \\
\hline Shoot Mn & $0.661^{* * *}$ & $0.304^{\mathrm{ns}}$ & $-0.753^{* * *}$ & $-0.684^{* * *}$ & $-0.513^{*}$ & $-0.403^{*}$ & $-0.673^{* * *}$ \\
\hline Shoot Zn & $0.860^{* * *}$ & $0.530^{* *}$ & $-0.734^{* * *}$ & $-0.785^{* * *}$ & $-0.646^{* * *}$ & $-0.661^{* * *}$ & $-0.731^{* * *}$ \\
\hline Root Cl & $-0.690^{* * *}$ & $-0.193^{\text {ns }}$ & $0.792^{* * *}$ & $0.756^{* * *}$ & 1.000 & $0.642^{* * *}$ & $0.778^{* * *}$ \\
\hline Root $\mathrm{Na}$ & $-0.618^{* *}$ & $-0.342^{\text {ns }}$ & $0.689^{* * *}$ & $0.720^{* * *}$ & $0.642^{* * *}$ & 1.000 & $0.634^{* * *}$ \\
\hline Root K & $0.787^{* * *}$ & $0.437^{*}$ & $-0.877^{* * *}$ & $-0.845^{* * *}$ & $-0.735^{* * *}$ & $-0.639^{* * *}$ & $-0.778^{* * *}$ \\
\hline Root Ca & $0.632^{* * *}$ & $0.317^{\mathrm{ns}}$ & $-0.554^{* *}$ & $-0.754^{* * *}$ & $-0.630^{* * *}$ & $-0.685^{* * *}$ & $-0.667^{* * *}$ \\
\hline Root Fe & $0.856^{* * *}$ & $0.696^{* * *}$ & $-0.620^{* *}$ & $-0.644^{* * *}$ & $-0.520^{* *}$ & $-0.497^{* *}$ & $-0.659^{* * *}$ \\
\hline Root $\mathrm{Cu}$ & $0.857^{* * *}$ & $0.596^{* *}$ & $-0.768^{* * *}$ & $-0.807^{* * *}$ & $-0.609^{* *}$ & $-0.594^{* *}$ & $-0.765^{* * *}$ \\
\hline Root Mn & $0.813^{* * *}$ & $0.595^{* *}$ & $-0.770^{* * *}$ & $-0.754^{* * *}$ & $-0.604^{* *}$ & $-0.522^{*}$ & $-0.736^{* * *}$ \\
\hline Root Zn & $0.740^{* * *}$ & $0.842^{* * *}$ & $-0.568^{* *}$ & $-0.511^{* *}$ & $-0.402^{*}$ & $-0.379^{*}$ & $-0.498^{* *}$ \\
\hline MDA & $-0.832^{* * *}$ & $-0.298^{\mathrm{ns}}$ & $0.835^{* * *}$ & $0.901^{* * *}$ & $0.778^{* * *}$ & $0.634^{* * *}$ & 1.000 \\
\hline Chla & $0.753^{* * *}$ & $0.298^{\text {ns }}$ & $-0.833^{* * *}$ & $-0.859^{* * *}$ & $-0.701^{* * *}$ & $-0.624^{* * *}$ & $-0.860^{* * *}$ \\
\hline Chlb & $0.459^{* *}$ & $0.098^{\text {ns }}$ & $-0.565^{* *}$ & $-0.552^{* *}$ & $-0.657^{* * *}$ & $-0.316^{\mathrm{ns}}$ & $-0.523^{* *}$ \\
\hline Carot & $0.835^{* * *}$ & $0.535^{* *}$ & $-0.867^{* * *}$ & $-0.781^{* * *}$ & $-0.592^{* *}$ & $-0.635^{* * *}$ & $-0.779^{* * *}$ \\
\hline SOD & $0.909^{* * *}$ & $0.494^{* *}$ & $-0.798^{* * *}$ & $-0.816^{* * *}$ & $-0.748^{* * *}$ & $-0.671^{* * *}$ & $-0.828^{* * *}$ \\
\hline CAT & $0.847^{* * *}$ & $0.315^{\mathrm{ns}}$ & $-0.870^{* * *}$ & $-0.897^{* * *}$ & $-0.757^{* * *}$ & $-0.639^{* * *}$ & $-0.873^{* * *}$ \\
\hline GR & $0.823^{* * *}$ & $0.551^{*}$ & $-0.760^{* * *}$ & $-0.756^{* * *}$ & $-0.513^{* *}$ & $-0.684^{* * *}$ & $-0.725^{* * *}$ \\
\hline APX & $0.704^{* * *}$ & $0.759^{* * *}$ & $-0.521^{* *}$ & $-0.423^{* *}$ & $-0.483^{* *}$ & $-0.512^{* *}$ & $-0.442^{*}$ \\
\hline
\end{tabular}

\&Levels of significance are represented by $P<0.05(*), P<0.01\left(^{* *}\right)$, and $P<0.001\left(^{* * *}\right)$ with n.s. meaning not significant

expansion (Huang et al., 2016). In the current study, in both the grafted and ungrafted plants, the leaf $\mathrm{K}$ content decreased with an increase in the $\mathrm{NaCl}$ concentration, and the leaf $\mathrm{K}$ content was higher in the grafted plants when compared to the ungrafted plants under salt stress (Figure 1), which showed that grafting promoted $\mathrm{K}$ transportation to the leaves and reduced $\mathrm{K}$ deficiency. Calcium plays a vital role in the formation of cell walls and relations among cells, while it also acts as a regulator in the cation-anion balance and as a catalyst for some enzymes. The decline in the contents of $\mathrm{Ca}$ in all of the combinations was assumed to have been a result of the transpiration rate decline under circumstances such as salt stress (Maggio et al., 2007). Under salt stress, some rootstocks have shown an ability to regulate $\mathrm{Na}$ partitioning from the shoots to younger and older leaves, and to achieve higher $\mathrm{Ca}$ to $\mathrm{Na}$ and $\mathrm{K}$ to $\mathrm{Na}$ ratios in the tips, fruit, and younger leaves when compared to ungrafted leaves. Micronutrients are vital for the growth of plants and they play roles in almost all metabolic and cellular processes, including energy metabolism, both primary and secondary metabolism, cellular defense, regulation of genes, processing of hormones, and transduction and reproduction of signals, in addition to being a catalyst in many antioxidant enzymes (Shahverd et al., 2020). With regards to the micronutrient concentrations in leaves and roots, the data herein showed a general increase under salt stress, except in the Cu contents of the leaves, which decreased in the grafted plants (Table 1). Several studies in the literature have reported that specific grafting combinations were more significantly efficient with regards to the absorption and transportation of nutrients like $\mathrm{N}, \mathrm{K}, \mathrm{Ca}, \mathrm{Fe}$, and other micronutrients, to the shoots when compared with ungrafted plants (AlJuthery et al., 2019).

Growth inhibition in plants is the result of decreased chlorophyll content, possibly due to ROSinduced chlorosis, photo-reduction, and triplet chlorophyll formation, which cause serious damage to photosystems I and II, and the formation of chlorophyll in plants (Singh et al., 2018). In the decreased chlorophyll contents were observed in the grafted and ungrafted plants under salt stress, while in the grafted salt-tolerant plants, and more specifically in SCP-2/TLR2 , a high chlorophyll content was determined (Figure 2). These results indicated that grafting mitigated the inhibition of photosynthesis that occurred due to salt stress. Carotenoids essentially play a critical part in light harvesting and oxidative damage protection through the deactivation of ${ }^{1} \mathrm{O}_{2}$, satisfying the excited triplet state in chlorophyll, and the enhancement of carotenoid synthesis as a way of protecting itself from photodamage caused by cell division arrest when exposed to salt stress (Singh et al., 2018). Ulas et al. (2020) indicated that higher chlorophyll (7.4\%) and carotenoid contents $(9.4 \%)$ of the grafted melons as compared with the nongrafted ones under salt stress.

A biomarker used for oxidative stress-induced lipid peroxidation is MDA content measurement or quantification (Kaushal, 2019). During salt stress, the main targets of ROS are membrane phospholipids that contain polyunsaturated fatty acids. The results of this include the degradation of fatty acids and lipid 
peroxidation, which generate a number of cytotoxic products like MDA. In the current study, the lipid peroxidation of the melon plants increased under salt stress. It was noted, however, that the grafted plants exhibited decreased MDA contents under salt stress when compared to the ungrafted salt-stressed plants, which suggested lower ROS accumulation and less damage to the membranes of the grafted plants (Figure 2). This increased effect on the accumulation of MDA could have been related to the higher accumulation of secondary metabolites, resulting in better stabilized subcellular structures, such as membranes and proteins, scavenge-free radicals, and cellular redox buffering potential under salt stress (Islam et al., 2016). Reducing the MDA content in grafted, stressed plants can be an effective mechanism for mitigating the activation of plant defenses. This process also guarantees membrane integrity and reduces the leakage of essential ions (Penella et al., 2016; Zhang et al., 2019). Similar results were also demonstrated by Ulas et al. (2020), who elucidated that our results clearly indicate that grafting with the Cucurbita maxima $\times$ C. moschata rootstocks had pronounced contributions to the biochemical responses of the scions (melon) under both control and salt stress conditions. ROS are produced as a result of the oxidative stress caused by, in this study, salt. High concentrations of ROS damage DNA, proteins, carbohydrates, and lipids, and hence their concentrations in plant cells must be controlled. ROS elimination, damage management, and repair can be controlled by detoxification signaling (Yang \& Guo, 2018). In melon tests, biochemical properties, such as chlorophyll, MDA content, and antioxidant enzyme activities, such as CAT, SOD, and APX, were shown to increase under salt stress when compared with selfgrafted and ungrafted plants (Fu et al., 2018). The SOD, CAT, GR, and APX activities of the grafted plants, SCP1/TLR-2 and SCP-2/TLR-2, were much higher in the current sample than those of the other combinations under salt stress. As a result of the increased antioxidant system activity in grafted plants, the MDA concentration was significantly decreased when compared to the ungrafted plants (Figure 3), indicating less oxidative harm. This suggested that the antioxidant enzyme mechanism worked efficiently in the grafted plants to scavenge overproduced $\mathrm{H}_{2} \mathrm{O}_{2}$, and thus protected the plants against toxicity to ROS under salt stress. The salttolerant grafted plants acquired improved salt stress tolerance as a result of their improved antioxidant system, which led to improved plant growth. According to He et al. (2009), grafted tomato plants were less affected by salt stress and rootstock efficiency in alleviating oxidative stress damage was the result of increased CAT activity and ascorbate-glutathione cycleinvolved enzymes, like APX and GR. The ability of grafted plants to alleviate the inhibition effects of salinity can be related to more efficient photosynthesis and enhanced enzymatic antioxidants in grafted plants (Shu et al., 2016). Yanyan et al. (2018) reported that the enhancement of salt tolerance in rootstocks was connected to antioxidant system activation, including those that scavenged ROS, such as POD, SOD, APX, and CAT. This suggested that the SOD/CAT detoxification mechanism worked efficiently in the salt-stressed plants that had been grafted with rootstock for the detoxification of high $\mathrm{H}_{2} \mathrm{O}_{2}$ levels, and therefore protected the plants from ROS toxicity. The grafted plants seemed to have achieved improved salt stress tolerance via the development of a strengthened antioxidant system, which then resulted in better development.

\section{Conclusion}

In the current study, significant differences were observed in the physiological and biochemical reactions in the grafted plant combinations under salt stress. The salt tolerance increase in the grafted plants was the result of using salt-tolerant rootstock, because the scions that were grafted onto the different rootstocks responded somewhat differently to salinity. Grafting can mitigate ion toxicity via the limitation of $\mathrm{Na}$ transport and, in some instances, $\mathrm{Cl}$ transport, to the shoots, and store the $\mathrm{Na}$ and $\mathrm{Cl}$ in the roots, which is a common mechanism of tissue tolerance. An effective antioxidant system that can reduce oxidative damage is significant for improving tolerance to salt in grafted plants. The results of the current study have demonstrated that grafting onto salt-tolerant rootstocks could be a technique that is an efficient, effective, and environmentally friendly way to eliminate or reduce yield losses as a result of salinity.

\section{Author Contribution}

Conceptualization: ŞK, ŞŞE, Investigation: ŞK, EK, Formal Analysis: ŞK, EK, Resources: ŞK, EK, Writing Original Draft Preparation: ŞK, Writing - Review \& Editing: ŞŞE. All authors read and approved the final manuscript.

\section{Acknowledgements}

Authors gratefully acknowledge United Genetics Turkey Tohum Fide A.Ş. for their collaboration and assistance with the successful accomplishment of this work.

\section{References}

Acosta-Motos, J. R., Ortuño, M. F., Bernal-Vicente, A., DiazVivancos, P., Sanchez-Blanco, M. J., \& Hernandez, J. A. (2017). Plant responses to salt stress: adaptive mechanisms. Agronomy, 7(1), https://doi.org/10.3390/agronomy7010018

Al-Juthery, H. W., Al-Swedi, F. G., Al-Taee, R. A., \& Al-Taey, D. K. (2019). Grafting of vegetable crops improve diseases control, salt and drought stress tolerance and nutrients, 
water use efficiency. International Journal of Botany, 4 (3), 108-114.

Arnon, D. I. (1949). Copper enzymes in isolated chloroplast: polyphenoloxidase in Beta vulgaris. Plant Physiology, 14, 1-15. http:// doi.org/10.1104/pp.24.1.1

Böhm, V., Fekete, D., Balázs, G., Gáspár, L., \& Kappel, N. (2017). Salinity tolerance of grafted watermelon seedlings. Biologia Futura, 68(4), 412-427. https://doi.org/10.1556/018.68.2017.4.7

Cakmak, I., \& Marschner, H. (1992). Magnesium deficiency and high light intensity enhance activities of superoxide dismutase, ascorbate peroxidase and glutathione reductase in bean leaves. Plant Physiology, 98, 12221226. https://doi.org/10.1104/pp.98.4.1222

Carillo, P., Annunziata, M. G., Pontecorvo, G., Fuggi, A., \& Woodrow, P. (2011). Salinity stress and salt tolerance. In: Shanker A. \& Venkateswarlu B. (Eds.), Abiotic Stress in Plants-Mechanisms and Adaptations, pp. 21-38. https://doi.org/10.5772/22331

Colla, G., Rouphael, Y., Leonardi, C., \& Bie, Z. (2010). Role of grafting in vegetable crops grown under saline conditions. Scientia Horticulturae, 127(2), 147-155. https://doi.org/10.1016/i.scienta.2010.08.004

Dasgan, H. Y., Bayram, M., Kusvuran, S., Coban, A. G., \& Akhoundnejad, Y. (2018). Screening of tomatoes for their resistance to salinity and drought stress. Journal of Biology, Agriculture and Healthcare, 8(24), 31- 37.

Edelstein, M., Plaut, Z., \& Ben-Hur, M. (2011). Sodium and chloride exclusion and retention by non-grafted and grafted melon and Cucurbita plants. Journal of Experimental Botany, 62(1), 177-184. https://doi.org/10.1093/jxb/erq255

Fu, Q., Zhang, X., Kong, Q., Bie, Z., \& Wang, H. (2018). Grafting onto pumpkin rootstock is an efficient alternative to improve melon tolerance to $\mathrm{NaCl}$ stress. European Journal of Horticultural Science, 83(6), 337-344. https://doi.org/10.17660/eJHS.2018/83.6.1

Fullana-Pericas, M., Ponce, J., Conesa, M. À., Juan, A., RibasCarbó, M., \& Galmés, J. (2018). Changes in yield, growth and photosynthesis in a drought-adapted Mediterranean tomato landrace (Solanum lycopersicum 'Ramellet') when grafted onto commercial rootstocks and Solanum pimpinellifolium. Scientia Horticulturae, 233,

70-77.

https://doi.org/10.1016/j.scienta.2018.01.045

Hammad, S. A., \& Ali, O. A. (2014). Physiological and biochemical studies on drought tolerance of wheat plants by application of amino acids and yeast extract. Annals of Agricultural Sciences, 59(1), 133-145. https://doi.org/10.1016/j.aoas.2014.06.018

He, Y., Zhu, Z., Yang, J., Ni, X., \& Zhu, B. (2009). Grafting increases the salt tolerance of tomato by improvement of photosynthesis and enhancement of antioxidant enzymes activity. Environmental and Experimental Botany, 66(2), 270-278. https://doi.org/10.1016/j.envexpbot.2009.02.007

Heath, R. L., \& Packer, L. (1968). Photoperoxidation in isolated chloroplasts. I. Kinetics and stoichiometry of fatty acid peroxidation. Archives of Biochemistry and Biophysics, 125(1), 189-198. https://doi.org/10.1016/00039861(68)90654-1

Islam, F., Yasmeen, T., Arif, M. S., Ali, S., Ali, B., Hameed, S., \& Zhou, W. (2016). Plant growth promoting bacteria confer salt tolerance in Vigna radiata by up-regulating antioxidant defense and biological soil fertility. Plant growth regulation, 80(1), 23-36. https://doi.org/10.1007/s10725-015-0142-y

Kaushal, M. (2019). Microbes in cahoots with plants: MIST to hit the jackpot of agricultural productivity during drought. International Journal of Molecular Sciences, 20(7), 1769. https://doi.org/10.3390/ijms20071769

Kiran, S., Kuşvuran, Ş., Ateş, C., \& Ellialtıoğlu, Ş. Ş. (2017). Some physiological properties and analysis of yield parameters of grafted and non-grafted eggplants under waterless conditions. Soil Water Journal, 6(2), 18-25. https://doi.org/10.21657/topraksu.339827

Kusvuran, S. (2012). Ion regulation in different organs of melon (Cucumis melo) genotypes under salt stress. International Journal of Agriculture \& Biology, 14, 141144.

Kusvuran, S., Kiran, S., \& Ellialtioglu, S. S. (2016). Antioxidant enzyme activities and abiotic stress tolerance relationship in vegetable crops. In: Shanker A.K. and Shanker C (Eds.) Abiotic and biotic stress in plants-recent advances and future perspectives. IntechOpen, London, pp. 481-503. https://doi.org/10.5772/62235

Lee, J. M. (1994). Cultivation of grafted vegetables I. current status, grafting methods, and benefits. HortScience, 29(4), 235-239.

Maggio, A., Raimondi, G., Martino, A., \& De Pascale, S. (2007). Salt stress response in tomato beyond the salinity tolerance threshold. Environmental and Experimental Botany, 59(3), 276-282. https://doi.org/10.1016/j.envexpbot.2006.02.002

Martinez-Vilalta, J., \& Garcia-Forner, N. (2016). Water potential regulation, stomatal behaviour and hydraulic transport under drought: deconstructing the iso/anisohydric concept. Plant, Cell and Environment, 40(6), 962-976. https://doi.org/10.1111/pce.12846

Muries, B., Carvajal, M., Carmen, M., \& Martinez-Ballesta, M. C. (2013). Response of three broccoli cultivars to salt stress, in relation to water status and expression of two leaf aquaporins. Planta, 237(5), 1297-1310. https://doi.org/10.1007/s00425-013-1849-5

Niu, M., Huang, Y., Sun, S., Sun, J., Cao, H., Shabala, S., \& Bie, Z. (2017). Root respiratory burst oxidase homologuedependent $\mathrm{H}_{2} \mathrm{O}_{2}$ production confers salt tolerance on a grafted cucumber by controlling $\mathrm{Na}^{+}$exclusion and stomatal closure. Journal of Experimental Botany, 69(14), 3465-3476. https://doi.org/10.1093/jxb/erx386

Nxele, X., Klein, A., \& Ndimba, B. K. (2017). Drought and salinity stress alters ROS accumulation, water retention, and osmolyte content in sorghum plants. South African Journal of Botany, 108, 261-266. https://doi.org/10.1016/j.sajb.2016.11.003

Penella, C., Nebauer, S. G., Quinones, A., San Bautista, A., López-Galarza, S., \& Calatayud, A. (2015). Some rootstocks improve pepper tolerance to mild salinity through ionic regulation. Plant Science, 230, 12-22. https://doi.org/10.1016/j.plantsci.2014.10.007

Penella, C., Landi, M., Guidi, L., Nebauer, S. G., Pellegrini, E., San Bautista, A., Remorini, D., Nali, C., López-Galarza, S., \& Calatayud, A. (2016). Salt-tolerant rootstock increases yield of pepper under salinity through maintenance of photosynthetic performance and sinks strength. Journal of plant physiology, 193, 1-11. https://doi.org/10.1016/i.jplph.2016.02.007

Penella, C., \& Calatayud, A. (2018). Pepper crop under climate change: Grafting as an environmental friendly 
strategy. In: Rao C. S., Shanker A. K., Shanker, C. (Eds.) Climate Resilient Agriculture: Strategies and Perspectives. IntechOpen, London, pp.129-155. https://doi.org/10.5772/intechopen.72361

Santa-Cruz, A., Martinez-Rodríguez, M. M., Perez-Alfocea, F., Romero-Aranda, R., \& Bolarin, M. C. (2002). The rootstock effect on the tomato salinity response depends on the shoot genotype. Plant Science, 162(5), 825-831. 9452(02)00030-4

Sarabi, B., Bolandnazar, S., Ghaderi, N., \& Ghashghaie, J. (2017). Genotypic differences in physiological and biochemical responses to salinity stress in melon (Cucumis melo L.) plants: Prospects for selection of salt tolerant landraces. Plant Physiology and Biochemistry, 119, 294-311. https://doi.org/10.1016/j.plaphy.2017.09.006

Shahverdi, M. A., Omidi, H., \& Damalas, C. A. (2020). Foliar fertilization with micronutrients improves Stevia rebaudiana tolerance to salinity stress by improving root characteristics. Brazilian Journal of Botany, 43(1), 55-65. https://doi.org/10.1007/s40415-020-00588-6

Shu, S., Gao, P., Li, L., Yuan, Y., Sun, J., \& Guo, S. (2016). Abscisic acid-induced $\mathrm{H}_{2} \mathrm{O}_{2}$ accumulation enhances antioxidant capacity in pumpkin-grafted cucumber leaves under $\mathrm{Ca}$ (NO3) $_{2}$ stress. Frontiers in Plant Science, 7, 1489. https://doi.org/10.3389/fpls.2016.01489

Simpson, C. R., King, S., Nelson, S. D., Jifon, J., Schuster, G., \& Volder, A. (2015). Salinity Evaluation for watermelon (Citrullus lanatus) grafted with different rootstocks. Subtropical Agriculture and Environments, 66, 1-6.

Singh, R., Upadhyay, A. K., Chandra, P., \& Singh, D.P. (2018). Sodium chloride incites Reactive Oxygen Species in green algae Chlorococcum humicola and Chlorella vulgaris: Implication on lipid synthesis, mineral nutrients and antioxidant system. Bioresource Technology, 270, 489497. https://doi.org/10.1016/i.biortech.2018.09.065

Tavakkoli, E., Fatehi, F., Coventry, S., Rengasamy, P., \& Mcdonald, G. K. (2011). Additive effects of $\mathrm{Na}^{+}$and $\mathrm{Cl}^{-}$ ions on barley growth under salinity stress. Journal Experimental Botany, 62(6), 2189-2203. https://doi.org/10.1016/j.plantsci.2004.07.032
Ulas, A., Aydin, A., Ulas, F., Yetisir, H., \& Miano, T. F. (2020). Cucurbita rootstocks improve salt tolerance of melon scions by inducing physiological, biochemical and nutritional responses. Horticulturae, 6(4), 66. https://doi.org/10.3390/horticulturae6040066

Ulas F., Ulas A., \& Yetisir H. (2019). Grafting for sustainable growth performance of melon (Cucumis melo) under salt stressed hydroponic condition. European Journal of Sustainable Development, 8(1), 201-210. https://doi.org/10.14207/ejsd.2019.v8n1p201

Turkan, I., Bor, M., Özdemir, F., \& Koca, H. (2005). Differential responses of lipid peroxidation and antioxidants in the leaves of drought-tolerant $P$. acutifolius Gray and drought-sensitive $P$. vulgaris $\mathrm{L}$. subjected to polyethylene glycol mediated water stress. Plant Science, 168(1),

223-231. https://doi.org/10.1016/i.plantsci.2004.07.032

Yang, L., Zhu, Y., Hu, C., Liu, Z., \& Zhang, G. (2006). Effects of $\mathrm{NaCl}$ stress on the contents of the substances regulating membrane lipid oxidation and osmosis and photosynthetic characteristics of grafted cucumber. Acta Botanica Boreali-Occidentalia Sinica, 26(6), 1195-1200.

Yang, Y., \& Guo, Y. (2018). Elucidating the molecular mechanisms mediating plant salt-stress responses. New Phytologist, 217(2), 523-539.

https://doi.org/10.1111/nph.14920

Yanyan, Y., Shuoshuo, W., Min, W., Biao, G., \& Qinghua, S. (2018). Effect of different rootstocks on the salt stress tolerance in watermelon seedlings. Horticultural Plant Journal, 4(6), 239-249. https://doi.org/10.1016/j.hpj.2018.08.003

Zhang, Z., Cao, B., Gao, S., \& Xu, K. (2019). Grafting improves tomato drought tolerance through enhancing photosynthetic capacity and reducing ROS accumulation. Protoplasma, 256(4), 1013-1024. https://doi.org/10.1007/s00709-019-01357-3

Zhu, J., Bie, Z., Huang, Y., \& Han, X. (2008). Effect of grafting on the growth and ion concentrations of cucumber seedlings under $\mathrm{NaCl}$ stress. Soil Science and Plant Nutrition, 54(6), 895-902. https://doi.org/10.1111/j.1747-0765.2008.00306.x 